\title{
Multicenter Study on the Immunogenicity and Safety of Two Recombinant Vaccines Against Hepatitis B
}

\author{
Reinaldo Menezes Martins/ ${ }^{+}$, Gilberta Bensabath*, Luiz Claudio Arraes**, \\ Maria de Lourdes Aguiar O liveira***, Juliana Custódio Miguel***, \\ Glayse Glayde Barbosa****, Luiz Antonio Bastos Camacho*****
}

\begin{abstract}
Comitê Técnico Assessor em Imunizações, Secretaria de Vigilância em Saúde, Ministério da Saúde, Av. Erico Veríssimo 430-102, 22621-180 Rio de Janeiro, Brasil *Instituto Evandro Chagas, Ministério da Saúde, Belém, PA, Brasil **Instituto MaternoInfantil de Pernambuco, Recife, PE, Brasil *** Departamento de Virologia, Centro de Referência Nacional de Hepatites Virais, Instituto Oswaldo Cruz-Fiocruz, Rio de Janeiro, RJ, Brasil ****Lar de Frei Luiz, Rio de Janeiro, RJ, Brasil *****Escola
\end{abstract}

Nacional de Saúde Pública-Fiocruz, Rio de Janeiro, RJ, Brasil

The immunogenicity and safety of a new recombinant hepatitis $B$ vaccine from the Instituto Butantan (Butang®) were evaluated in a multicenter, double-blind, prospective equivalence study in three centers in Brazil. Engerix $B \circledR$ was the standard vaccine. A total of 3937 subjects were recruited and $2754(70 \%)$ met all protocol criteria at the end of the study. All the subjects were considered healthy and denied having received hepatitis B vaccine before the study. Study subjects who adhered to the protocol were newborn infants (566), children 1 to 10 years old (484), adolescents from 11 to 19 years (740), adults from 20 to 30 years (568), and adults from 31 to 40 years (396). Vaccine was administered in three doses on the schedule 0, 1, and 6 months (newborn infants, adolescents, and adults) or 0, 1, and 7 months (children). Vaccine dose was intramuscular $10 \mu \mathrm{g}$ (infants, children, and adolescents) or $20 \mu \mathrm{g}$ (adults). Percent seroprotection (assumed when anti-HBs titers were $\geq 10 \mathrm{mIU} / \mathrm{ml}$ ) and geometric mean titer $(\mathrm{mIU} / \mathrm{ml})$ were: newborn infants, $93.7 \%$ and 351.1 (Butang $\left.{ }^{\circledR}\right)$ and $97.5 \%$ and 1530.6 (Engerix B®); children, $100 \%$ and 3600.0 (Butang $®$ ) and $97.7 \%$ and 2753.1 (Engerix $B \circledR$ ); adolescents, $95.1 \%$ and 746.3 (Butang®) and $96 \%$ and 1284.3 (Engerix $B($ ); adults $20-30$ years old, $91.8 \%$ and 453.5 (Butang $($ ) and $95.5 \%$ and 1369.0 (Engerix $B \circledR$ ); and adults $31-40$ years old, $79.8 \%$ and 122.7 (Butang $\left.{ }^{\circledR}\right)$ and $92.4 \%$ and 686.2 (Engerix $B \circledR$ ). There were no severe adverse events following either vaccine. The study concluded that Butang ${ }^{\circledR}$ was equivalent to Engerix $B{ }^{\circledR}$ in children, and less immunogenic but acceptable for use in newborn infants, adolescents, and young adults.

Key words: hepatitis B vaccine - recombinant vaccines - immunization

Butang ${ }^{\circledR}$ hepatitis B vaccine has been developed and is produced by Instituto Butantan (IB), with genetic engineering technology, using Hansenulla polymorpha yeast cells. The advantage of this yeast expression system as compared to other expression systems (such as Saccharomyces cerevisiae) is that expression is estimated to be 4 to 10 times higher, helping to decrease the production costs (Hieu et al. 2002). The vaccine contains (in $1 \mathrm{ml}$ ) $20 \mu \mathrm{g}$ of $\mathrm{HBs} \mathrm{Ag}$, aluminium hydroxide up to $1.25 \mathrm{mg}$ (in Aluminium), and thimerosal $0.05 \mathrm{mg}$. In pre-licensure studies Butang showed low reactogenicity and good immunogenicity in adults (Costa et al. 1997, Ioshimoto et al. 1999), but additional studies were considered necessary.

From 1997 to 2003, 163,836,465 doses of hepatitis B vaccine have been purchased by the Ministry of Health, $54 \%$ of which imported and $46 \%$ produced domestically. Vaccination is provided free of charge by public services. By 1995, hepatitis B vaccine was responsible for $73 \%$ of vaccine costs in the National Immunizations Program

Financial support: Brazilian Ministry of Health

${ }^{+}$Corresponding author. Fax: +55-21-2493.7213. E-mail: reinaldomm@ig.com.br

Received 20 July 2004

Accepted 6 October 2004
(NIP), although at that time vaccine coverage was low (Gadelha \& Azevedo 2003). Prices have been dropping steadily, so that by now one dose costs around US\$0.28.

We report the results of a study conducted to assess the performance of the Butantan hepatitis B vaccine, compared to Engerix $B \circledR$, which is produced using as expression system $S$. cerevisiae and widely used and acknowledged as safe and immunogenic both in Brazil and abroad. Development and production of hepatitis B vaccine by IB is part of a project to strengthen the Brazilian vaccine industry, a policy that has been pursued by the Brazilian NIP as a means to decrease vulnerability to market uncertainties. In the past, immunization activities have been jeopardized by insufficient availability of vaccines from international manufacturers. The capacity to both produce a vaccine and demonstrate its satisfactory performance with high scientific standards is strategic for developing countries.

\section{MATERIALS AND METHODS}

Study design - This was a double-blind, prospective equivalence study in three centers in Brazil to assess and compare the immunogenicity of a Brazilian hepatitis B recombinant vaccine (Butang®, $20 \mu \mathrm{g} / \mathrm{ml}$ ), to a commercially available vaccine as an active control (Engerix $B \AA, 20 \mu \mathrm{g} /$ $\mathrm{ml}$ ). Three centers in different regions of the country followed the same research protocol and addressed differ- 
ent age groups: Instituto Evandro Chagas (IEC) in Belém, Pará (adults and adolescents), Instituto Materno-Infantil de Pernambuco (IMIP) in Recife, Pernambuco (newborns), and Educandário Social Lar de Frei Luiz (LFL) in Rio de Janeiro (children aged 1 to 11 years).

The study was conducted from mid-2001 almost simultaneously in the different centers, and field work was completed in August 2002. The final laboratory studies were completed in January 2003.

Based on previous studies with Engerix $B \AA$ at the National Reference Laboratory on Viral Hepatitis at Fiocruz in Rio de Janeiro (NRLVH) in full-term newborns (Motta et al. 2002) and on other studies in children and adolescents (Ferreira et al. 1993, André 1989, Greenberg 1993, Adkins \& Wagstaff 1998, Mahoney \& Kane 1999, Assad 1999), we anticipated $98 \%$ of seroprotection (SP), that is, antibody titer $\geq 10$ milli International Units per millilitre $(\mathrm{mIU} / \mathrm{ml})$. Based on a more conservative estimate $-95 \%-$ we found that 258 subjects would be necessary for $80 \%$ power to show equivalence defined as difference in seroconversion rates not larger than 5 percentage points between the two vaccines. In adults aged 21-40 years, 624 subjects would be necessary, considering $90 \%$ as the reference for seroprotection. This last calculation was based on previous studies in adults with Engerix $B{ }^{\circledR}$ at the same Brazilian National Reference Laboratory (not published).

Since it had been demonstrated that $310 \mu \mathrm{g}$-doses of Engerix $B{ }^{\circledR}$ in adolescents provided high titers of antiHBs and high seroprotection, similar to those obtained with $20 \mu \mathrm{g}$, it was decided to give the same $10 \mu \mathrm{g}$ dose of both vaccines to newborn infants, children, and adolescents (Leroux-Roels et al. 2000).

IEC subjects were recruited at schools (adolescents) and military units (adults). Newborns were recruited from IMIP, a private institution, after prenatal screening for HBsAg.

LFL is a private charitable institution, and subjects were recruited at the community level with the approval of the neighbourhood residents' association.

Subjects or their guardians gave written consent to the study, following explanation of the study objectives. The study protocol was approved by ethics committees from the institutions involved.

Subjects identified during initial screening as infected with hepatitis B virus were offered treatment at reference centers. Those who failed to demonstrate seroprotection after the third dose of vaccine were offered additional doses.

For operational reasons, allocation was systematic: at IEC and IMIP, by day of the week, with adjustment for equalizing the two arms of the study; at LFL, by month of birth, without adjustment.

The type of vaccine administered was not revealed to either the vaccine recipients or the research team. A modified scheme to prevent study participants from discovering their study arm consisted of having original vaccine vial labels covered with coded labels at the Brazilian National Center for Storage and Distribution of Immunobiologicals, a division of the Ministry of Health. Although training of study personnel emphasized the importance of not revealing the study arm, strict blinding was not guaranteed, given the differences in vial sizes. Blood samples were labeled only with a number and the name of the source institution, in order to conceal from laboratory personnel the study group to which the specimen belonged.

Inclusion and exclusion criteria - Only healthy subjects who informed not having received previous hepatitis $B$ vaccination were eligible for the study. Candidates who presented a positive or inconclusive HBV serological marker in the first blood sample or were anti-HBc positive after the third dose were excluded from the analysis of adherence to protocol.

Newborn infants should have at least $2 \mathrm{~kg}$ of birth weight. In this group HBV antibodies were not considered a reason for exclusion, as they reflected passive immunity from the mother. Only newborns of mothers with HBsAg were excluded.

Full compliance to the study protocol was defined by the following criteria: providing a blood sample for serology before the first dose; receiving three doses of vaccine; interval between the first two doses $\geq 28$ days and $\leq 90$ days, interval between the second and third doses of at least 120 days, interval between the third dose and final blood sample $\geq 28$ days and $\leq 100$ days, and blood sample and serology after the third dose.

Nutritional evaluation - Subjects were measured (weight and recumbent or vertical height as indicated) and classified into nutritional categories. For children $>1$ to $<2$ years $z$-score of weight for height (CDC 2000) was used as follows: underweight $=\mathrm{z}<-2$; adequate $=\mathrm{z} \geq 2$ to $\leq 2$; overweight $=\mathrm{z}>2$; children $\geq 2$ years and adolescents: $\mathrm{z}$-score of BMI - body mass index - (CDC 2000): underweight $=\mathrm{z}<-2$; adequate $=\mathrm{z} \geq 2$ to $\leq 2$; overweight $=\mathrm{z}>2$; adults $>20$ years (Bray 1989): underweight $=$ BMI $<20$; adequate $=$ BMI 20-24.9; overweight $=$ BMI 25-29.9; obese $=\mathrm{BMI} \geq 30$. All newborns were considered adequate nutritionally, as we included only those with $\geq 2 \mathrm{~kg}$ of birth weight, a group known to respond very well to hepatitis B vaccine (Saari 2003).

Vaccine administration - Vaccine administration was intramuscular in the deltoid (adults, adolescents, and children) and in the antero-lateral thigh (infants). Needle size was chosen according to fat thickness at the injection site. In general, the needles used were $24 \mathrm{G} 3 / 4$ in infants and children and $22 \mathrm{G} 1$ or $22 \mathrm{G} 11 / 4$ in adolescents and adults. For both vaccines, a dose of $10 \mu \mathrm{g}(0.5 \mathrm{ml})$ was administered to infants, children and adolescents and 20 $\mu \mathrm{g}(1 \mathrm{ml})$ to adults. The recommended schedule was 0,1 , and 6 months.

Due to the expiration date of Butang®, the vaccine lot for the first two doses was different from the lot used for the third dose. With Engerix $B \AA$, the same lot was used for all three doses.

Laboratory tests - Serological studies were performed at IEC and at the Department of Virology of the Oswaldo Cruz Foundation (Fiocruz), the Brazilian Ministry of Health reference laboratories for viral hepatitis. Both laboratories used the methods described below.

Serological analysis was conducted on blood samples drawn on two occasions: just prior to the first vaccine dose, and from 28-100 days after the third dose. At IEC an 
additional blood sample was drawn in $20 \%$ of volunteers, just prior to the third dose.

Serum samples collected before the first dose were screened for HBV markers (HBsAg, anti-HBs, and anti$\mathrm{HBc})$. Anti-HBc and quantitative determination of antiHBs were performed after the third dose.

$\mathrm{HBsAg}$, anti-HBs, and anti-HBc were evaluated by the enzyme immunoassay from Hepanostika ${ }^{\circledR}$ Organon [Marcy l'Etoile, France]: HBsAg - HBsAg Uniform II; AntiHBc - Hepanostika anti-HBc Uniform; anti-HBs Hepanostika anti-HBs.

Automatic quantitative analysis of anti-HBs (mIU/ml) was performed using the Access ${ }^{\circledR}$ AbHBsII immunoenzymatic assay from Beckman Coulter (Fullerton, California, US).

A sub-sample of 100 blood samples selected randomly from sera tested at the Evandro Chagas Laboratory (from adolescents and adults) were recoded and sent to be retested for quantitative antiHBs at the Fiocruz laboratory. Likewise, 100 blood samples selected randomly from blood samples tested initially at Fiocruz were recoded and sent to be retested at Evandro Chagas Laboratory. AntiHBs levels were measured without knowledge of previous results. Reliability of the measurements was assessed by the intra-class correlation coefficient (ICC) stratified by origin of the samples.

Data base and analysis - Data were entered into an Epi-Info database (Dean et al. 1994), and analyzed with SPSS v. 11 (SPSS Inc., Chicago, US, 1999).

All subjects entered into the database remained there, even if they failed to adhere to the study protocol. Subjects found to have received hepatitis vaccine outside the study after it began were excluded from analysis.

Two variables were considered for anti-HBs quantitative evaluation after the third dose: seroprotection defined as anti-HBs $\geq 10 \mathrm{mIU} / \mathrm{ml}$ (primary outcome) and anti-HBs titers in $\mathrm{mIU} / \mathrm{ml}$ (secondary outcome). Similar criteria were used for evaluation of immunogenicity after the second dose (secondary outcomes).

Seroprotection and immunogenicity were evaluated for all subjects adhering to the protocol, and for all subjects with quantitative anti-HBs results, including noncompliers, so that any exclusion bias could be detected. These criteria were used for analysis of the final blood sample (after the third dose) and also for the sample prior to the third dose. In the latter case, adherence to protocol was verified at the moment of the second blood sample, just prior to the third dose.

The response of primary interest was the percentage of vaccines achieving a seroprotective level of anti-HBs after the third dose of vaccine $(\geq 10 \mathrm{mIU} / \mathrm{ml})$, while measures of secondary interest were the percentage achieving seroprotection after the second dose and the geometric mean titer (GMT) of anti-HBs after the second and third doses of vaccine.

Differences in the proportions of seroprotection (Butang $\AA$ - Engerix B $®$ ) and $90 \%$ confidence intervals were calculated, as has been recommended for equivalence studies (Blackwelder 1998). A-5\% difference was accepted as the limit for defining equivalence between the two vaccines. The null hypothesis of superiority of
Engerix $B \circledR$ was rejected when the lower limit of the confidence interval was not lower than $-5 \%$.

The ratio between the geometric mean anti-HBs titers (GMT) for the two vaccines after the third dose and the corresponding $90 \%$ confidence intervals were calculated. The null hypothesis of superiority of Engerix $B{ }^{\circledR}$ was rejected when the lower limit of the confidence interval for the ratio GMT Butang $\AA / \mathrm{GMT}$ Engerix ${ }^{\circledR}$ was higher than 0.67 .

To estimate the statistical significance of the difference in proportions between seroprotected versus nonseroprotected, one-sided chi-square and Fisher exact test were used. The $90 \%$ confidence intervals for this difference were calculated by the large samples method with Fleiss continuity correction. Logistic regression and multiple regression techniques were applied to adjust for imbalances between groups in relevant covariates.

\section{RESULTS}

A substantial proportion of study participants (particularly among adults and newborns) failed to meet all the protocol requirements, due to serological evidence of previous vaccination, previous or concurrent infection or loss to follow up (Table I). The proportion of non-compliant participants was similar across comparison groups. Results for adult vaccines were partitioned into two sets for descriptive summarization and analysis because Butang ${ }^{\circledR}$ was clearly less immunogenic in older (31-40 years) as opposed to younger (20-30 years) (Table I).

In newborns, only two babies were excluded because of positive serology before first dose, in both cases due to HBsAg positivity in their mothers.

In children before the first vaccine dose, there was serological evidence of previous vaccination (positive anti-HBs was the only marker found) in $2.8 \%$ of subjects, mostly in children under 4 years of age, an age group that represented $11.5 \%$ of recruited children and $7.4 \%$ of those who adhered to protocol. Another $4 \%$ of subjects had some other positive or inconclusive HBV marker and were also excluded from the analysis of adherence to protocol.

At IEC, positive serology before the first dose caused aproximately $15 \%$ of losses. In adolescents, positive serology indicated previous vaccination in most cases. In adults 31-40 years old, positive serology were mostly from prior infection, while in young adults (20-30 years old) there was a similar percentage of subjects with serological evidence of prior vaccination or infection.

Study subjects in the Butang ${ }^{\circledR}$ and Engerix $B \circledR$ groups had a balanced distribution by age, sex, nutritional status, and intervals between doses and between last dose and blood collection, except sex in adolescents, where there was a significantly larger proportion of females among subjects vaccinated with Butang ${ }^{\circledR}$. The statistical difference between 2nd and 3rd dose in adolescents and adults has no biological meaning (Table II).

Immunogenicity - Retesting of sera collected after dose 3 showed very high agreement between the two laboratories. Comparison of the $\log \mathrm{N}$ transformed anti-HBs titers showed an ICC of 0.975 (95\% CI: 0.882-0.990) for the sera tested first at IEC and 0.995 (95\% CI: 0.992-0.997) for those originally tested at NRLVH. 


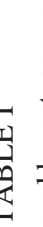

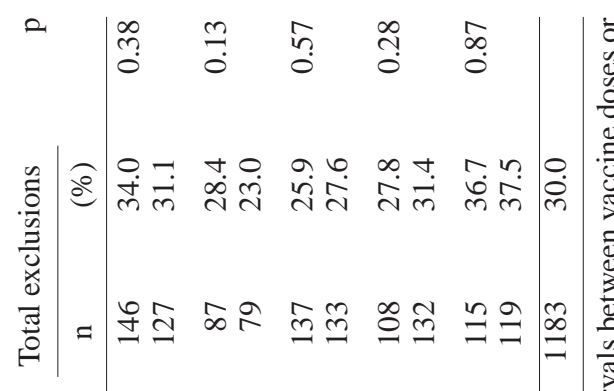

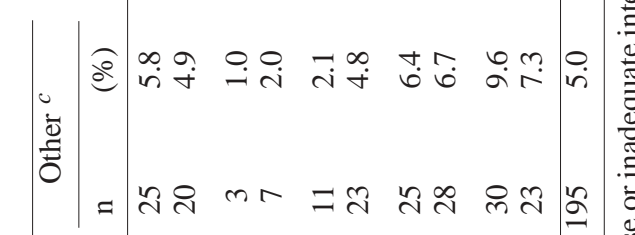

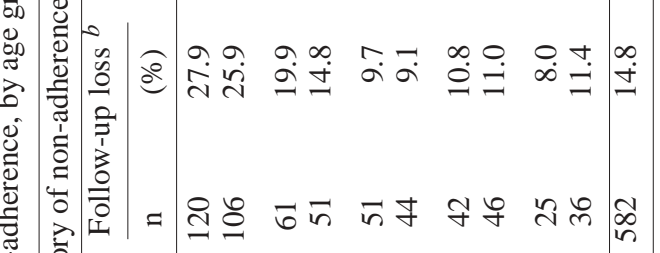

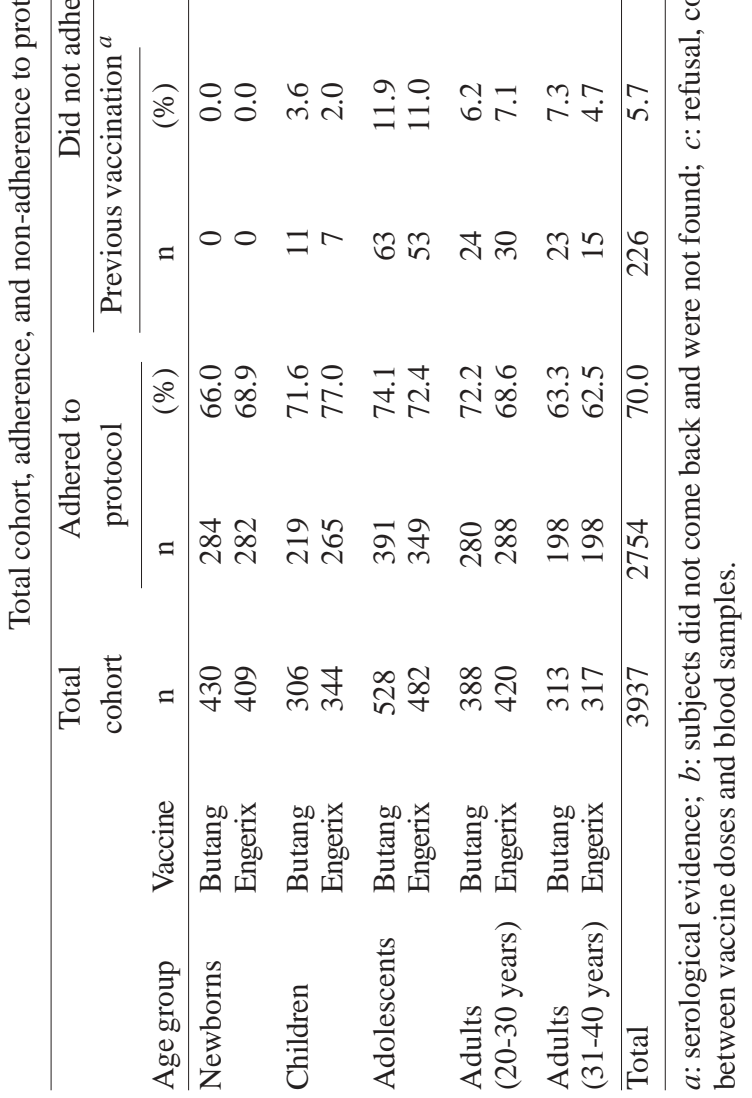

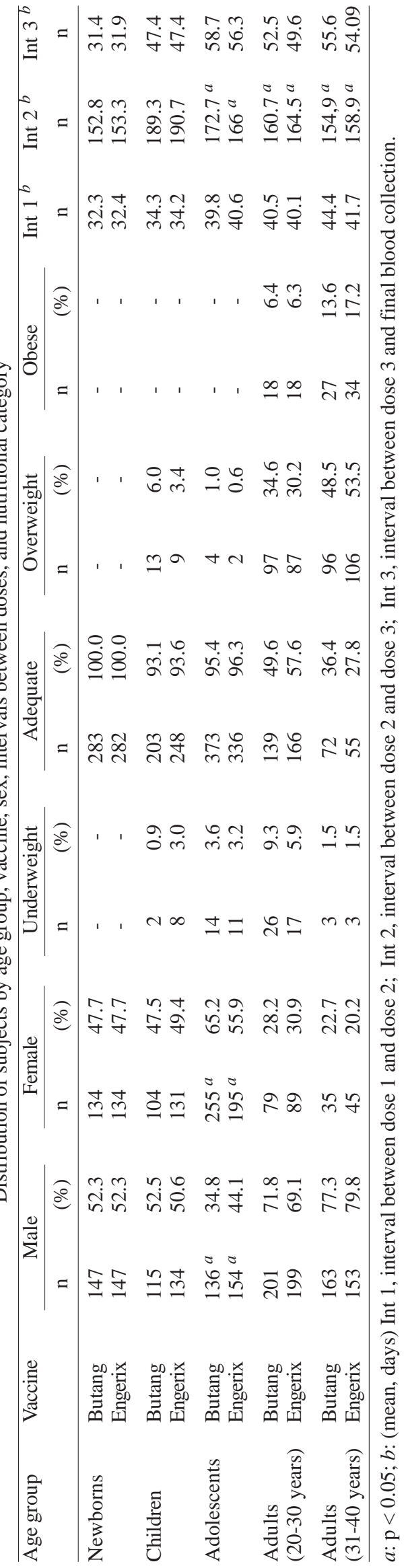


For both vaccines, proportions of seroprotection (SP) and geometric mean titers (GMT) were maximal in children (Table III). In newborn infants and adolescents, SP rates were similar whereas in adults Engerix performed much better. Children aged 1-10 years showed the strongest immune response, which decreased with age, particularly in the Butang group. Considering SP and GMT, Engerix $B \circledR$ performed better than Butang ${ }^{\circledR}$, except in children 110 years of age, for whom vaccines could be considered equivalent, because the confidence limits of the difference in proportions and of the GMT ratio were within the limits set to define equivalence between the vaccines. Among adolescents, the data showed equivalence in SP but not in GMT. For newborn infants, adults 20-30 years of age, and especially in adults 31-40 years of age, confidence limits were outside those limits both for differences in seroprotection rates and GMT (Table III).

Conventional categories of nutritional status did not discriminate study subjects. There were very few individuals in the "underweight" and "obese" categories (Table II). BMI in adults and $z$ scores of weight for age in children were not correlated with magnitude of immune response (see multivariate analysis below).

The difference in immunogenicity between Butang ${ }^{\circledR}$ and Engerix $B \circledR$ was greater in newborns and adults, and GMT was consistently higher in females in all age groups. Age and sex appeared to modify the comparative effects of the vaccines (Tables III and IV).
On logistical regression, seroprotection was significantly associated with type of vaccine in older adults $(>31$ years old) only. In young adults (20-30 years old) BMI and sex were independent predictors and confounders of the association of type of vaccine and seroprotection, which showed marginal statistical significance (odds ratio $=1.85 ; \mathrm{p}=0.09$ ).

In multiple regression, the type of vaccine was a significant predictor of the magnitude of the immune response (anti-HBs titers) in all age groups, adjusting for relevant covariates. The only significant modification of the effect of vaccine was found in children: in boys but not in girls the type of vaccine explained part of the difference in anti-HBs titers between vaccination groups. Among study subjects with age above 11 years, women had a stronger immune response compared to men. Nutritional status was an independent predictor of the strength of immune response only in young adults (higher BMI had weaker immune response) and newborns (larger infants had stronger immune response). The effect of BMI on the immune response among adolescents was not conclusive (marginal statistical significance).

Immune response after two doses was evaluated in a sub-sample of adolescents $\left(\mathrm{N}=115\right.$ Butang ${ }^{\circledR}$ and 160 Engerix $B \circledast$ ), 20-30-year-old adults $\left(\mathrm{N}=105\right.$ Butang ${ }^{\circledR}$ and 90 Engerix $B \circledR)$, and 31-40-year-old adults $\left(\mathrm{N}=47\right.$ Butang ${ }^{\circledR}$ and 67 EngerixB $\left.{ }^{\circledR}\right)$. Seroprotection rates (GMT) were respectively $60 \%$ (13.8 $\mathrm{mIU} / \mathrm{ml}), 61 \%(16.4 \mathrm{mIU} / \mathrm{ml})$, and

TABLE III

Proportions and differences in proportions of seroprotection (SP), geometric mean titers (GMTs), and ratio of GMTs after third dose of Butang $®$ and Engerix $B \circledR$ in subjects that adhered to protocol

\begin{tabular}{|c|c|c|c|c|c|c|c|c|}
\hline \multirow{2}{*}{$\begin{array}{l}\text { Institution } \\
\text { (age groups) }\end{array}$} & \multicolumn{2}{|c|}{$\mathrm{N}$} & \multicolumn{2}{|c|}{$\% \mathrm{SP}$} & \multirow{2}{*}{$\begin{array}{c}\% \text { difference in SP } \\
(90 \% \text { IC) }\end{array}$} & \multicolumn{2}{|c|}{ GMT } & \multirow{2}{*}{$\begin{array}{l}\text { GMT ratio } \\
(90 \% \text { IC) }\end{array}$} \\
\hline & Butang & Engerix & Butang & Engerix & & Butang & Engerix & \\
\hline $\begin{array}{l}\text { IMIP } \\
\text { (newborns) }\end{array}$ & 284 & 282 & 93.7 & 97.5 & $\begin{array}{c}-3.8 \\
(-7.0 \text { to }-0.6)\end{array}$ & 351.1 & 1530.6 & $\begin{array}{c}0.23 \\
(0.17 \text { to } 0.31)\end{array}$ \\
\hline $\begin{array}{l}\text { LFL } \\
\text { (1-10 years) }\end{array}$ & 219 & 265 & 100.0 & 97.7 & $\begin{array}{c}2.3 \\
(0.4 \text { to } 4.2)\end{array}$ & 3600 & 2753.1 & $\begin{array}{c}1.31 \\
(0.94 \text { to } 1.81)\end{array}$ \\
\hline $\begin{array}{l}\text { IEC } \\
\text { (11-19 years) }\end{array}$ & 391 & 349 & 95.1 & 96.0 & $\begin{array}{c}-0.9 \\
(-3.7 \text { to } 1.9)\end{array}$ & 746.3 & 1284.3 & $\begin{array}{c}0.58 \\
(0.44 \text { to } 0.76)\end{array}$ \\
\hline $\begin{array}{l}\text { IEC } \\
\text { (20-30 years) }\end{array}$ & 280 & 288 & 91.8 & 95.5 & $\begin{array}{c}-3.7 \\
(-7.4 \text { to } 0.02)\end{array}$ & 453.5 & 1369.0 & $\begin{array}{c}0.33 \\
(0.24 \text { to } 0.47)\end{array}$ \\
\hline $\begin{array}{l}\text { IEC } \\
\text { (31-40 years) }\end{array}$ & 198 & 198 & 79.8 & 92.4 & $\begin{array}{c}-12.6 \\
(-18.7 \text { to }-6.5)\end{array}$ & 122.7 & 686.2 & $\begin{array}{c}0.18 \\
(0.12 \text { to } 0.28)\end{array}$ \\
\hline
\end{tabular}

SP: seroprotection (antibody titer $\geq 10 \mathrm{mIU} / \mathrm{ml}$ ); GMT: geometric mean titer in mIU/ml; IMIP: Instituto Materno-Infantil de Pernambuco; LFL: Lar Frei Luiz, Rio de Janeiro; IEC: Instituto Evandro Chagas, Belém, PA

TABLE IV

Geometric mean titers, GMT (mIU/ml) and seroprotection (SP) (\%) by vaccine, sex, and age group in subjects that adhered to the study protocol

\begin{tabular}{|c|c|c|c|c|c|c|c|c|c|c|c|}
\hline \multirow[t]{2}{*}{ Vaccine } & \multirow[t]{2}{*}{ Sex } & \multicolumn{2}{|c|}{ Newborns } & \multicolumn{2}{|c|}{ Children } & \multicolumn{2}{|c|}{ Adolescents } & \multicolumn{2}{|c|}{ Adults $20-30$ years } & \multicolumn{2}{|c|}{ Adults $31-40$ years } \\
\hline & & GMT & SP & GMT & SP & GMT & SP & GMT & SP & GMT & SP \\
\hline \multirow[t]{2}{*}{ Butang } & Male & 325.3 & 90.5 & 2911.7 & 100.0 & 602.4 & 94.1 & 312.6 & 89.6 & 99.3 & 78.0 \\
\hline & Female & 390.3 & 97.0 & 4551.9 & 100.0 & 836.6 & 95.7 & 1169.0 & 97.5 & 327.9 & 88.6 \\
\hline \multirow[t]{2}{*}{ Engerix B } & Male & 1426.2 & 97.3 & 1384.5 & 95.5 & 1045.1 & 95.5 & 905.1 & 94.5 & 541.9 & 91.5 \\
\hline & Female & 1662.0 & 97.8 & 5561.9 & 100. & 1511.4 & 96.4 & 3452.3 & 97.8 & 1531.2 & 95.6 \\
\hline
\end{tabular}


$44.7 \%$ (7.8 mIU/ml) with Butang®, and $78.8(37.7 \mathrm{mIU} / \mathrm{ml})$, $82.2(36.3 \mathrm{mIU} / \mathrm{ml})$, and $74.6(31.2 \mathrm{mIU} / \mathrm{ml})$ with Engerix $\mathrm{B} \circledast$.

Safety - Adverse events were actively searched for and no serious adverse event attributable to the vaccines was observed in any study subject. Adverse events following the previous dose led to interruption of the vaccine schedule and elimination from the study in 13 cases ( 8 with Butang ${ }^{\circledR}$ and 5 with Engerix $B \circledR$ ), but in only 2 cases there was a clear indication of a causal relationship to vaccination: generalized pruritus in 1 adolescent and generalized urticaria in 1 adult. Both occurred soon after Engerix $B \circledR$, with full and fast recovery.

\section{DISCUSSION}

A comparison between different studies on the immunogenicity of hepatitis B vaccines is difficult, due to differences in vaccine characteristics and formulation, vaccination schedules, vaccination sites, injection procedures, timing of blood sampling, sensitivity of laboratory methods, and unexplained factors, resulting in a wide range of seroprotection and anti-HBs geometric mean titers (GMTs) with the same vaccine (Andre 1989, Greenberg 1993, Adkins \& Wagstaff 1998, Mahoney \& Kane 1999, Assad 1999, Keating \& Noble 2003).

Overall, in the present study, after 3 doses, Butang was equivalent to Engerix B in children and less immunogenic in newborn infants, adolescents, and adults. After 2 doses, in adolescents and adults, Butang was less immunogenic than Engerix B.

Our results in adolescents are similar to those obtained by Baldy with 3 doses of $10 \mu \mathrm{g}$ of Butang or Engerix B (Baldy et al. 2004). Our finding of decreased immunogenicity after 30 years with Butang is in agreement with a recent meta-analysis of the effect of age on immunologic response to recombinant hepatitis B vaccine (Fisman et al. 2002). The effect of sex and nutritional status on the immune response to vaccination against hepatitis B had also been reported before, but have no clear biological explanation.

The reason is not entirely clear for the somewhat lower results of immunogenicity from Engerix $B{ }^{\circledR}$ after 3 doses in adults and after two doses in adolescents and adults, compared to those reported in the literature, but this may be due to lower sensitivity of the laboratory test used. Although the comparability of test results obtained by the two laboratories involved in the study was guaranteed by the high degree of agreement obtained with blind retesting, commercial laboratory kits do vary in accuracy.

It is also not clear why Butang ${ }^{\circledR}$ displayed lower immunogenicity than Engerix $B \circledR$, since the two vaccines theoretically had the same concentration of HBsAg. It is possible that differences caused by different expression systems, different methods of quantification of $\mathrm{HBsAg}$ content by manufacturers, or minor differences in vaccine composition, account for the immunological difference, as has been reported (ul-Haq et al. 2003, Vanlandschoot et al. 2003).

Lack of randomization, losses to follow-up, and vulnerable blinding of allocation were the main limitations of this study. However, systematic allocation appears to have generated comparable, well-balanced groups in terms of sex and age, which were the relevant prognostic variables. Therefore, allocation does not appear to have appreciably influenced the results. Results were consistent across institutions and age groups, except for children (LFL center), which were scrutinized in search of protocol violations, and none were found that might have influenced the immunogenicity results. Among the study's strengths were its large sample size approached with the same research protocol, homogeneous immunization procedures, precise and accurate laboratory methods used in strictly blinded samples, stringent criteria for adherence to proto$\mathrm{col}$, and independence in relation to the vaccine manufacturers. The high agreement on serological results after blinded cross-retesting of samples between the two reference laboratories ensured the confidence in the laboratory evaluation of immunogenicity.

Butang ${ }^{\circledR}$ was highly immunogenic and equivalent to Engerix $B \circledR$ in children, but less immunogenic in newborn infants, adolescent and adults. This study reinforces the concept that each hepatitis B vaccine produced by different manufacturers must be viewed as a distinct product. There is no minimum requirement for antigen content of a hepatitis B vaccine, and based on the results of clinical trials, manufacturers should establish the protein/antigen content of their vaccine (WHO 2001). The Butantan Institute vaccine showed satisfactory performance in this clinical trial, which support its use in younger age groups. However, there is room for further improvement in its immunogenicity, particularly in adults. The implications of the comparatively lower immunogenicity for individuals with immunodeficiency and for the duration of protection remain to be seen.

\section{ACKNOWLEDGEMENTS}

To Jarbas Barbosa da Silva Júnior, Maria de Lourdes de Souza Maia, Sirlene Pereira, Maria Regina Fernandes de Oliveira, Margarita Maria Urdaneta Gutierrez, João Leonel Batista Estery, José Carlos de Melo Negrão (Ministry of Health); Clara Yoshida and Lia Lewis (Brazilian Reference Laboratory on Viral Hepatitis of the Oswaldo Cruz Institute, Rio de Janeiro); Emidio Cavalcanti de Albuquerque (Maternal and Child Institute of Pernambuco); Ronaldo Luiz Gazolla (Lar de Frei Luiz, Rio de Janeiro).

\section{REFERENCES}

Adkins JC, Wagstaff AJ 1998. Recombinant hepatitis B vaccine. A review of its immunogenicity and protective efficacy against hepatitis B. Biodrugs 10: 137-158.

André FE 1989. Summary of safety and efficacy data on a yeast-derived hepatitis B vaccine. Am J Med 87 (Suppl. 3A): $14 \mathrm{~S}-20 \mathrm{~S}$.

Assad S, Francis A 1999. Over a decade of experience with a yeast recombinant hepatitis B vaccine. Vaccine 18:57-67.

Baldy JLS, Lima GZ, Morimoto HK, Reiche EMV, Matsuo T, Mattos ED, Pulga LC 2004. Immunogenicity of three recombinant hepatitis B vaccines administered to students in three doses containing half the antigen amount routinely used for adult vaccination. Rev Inst Med Trop São Paulo 46: 103-107.

Blackwelder WC 1998. Equivalence trials. In P Armitage, T Colton (eds), Encyclopedia of Statistics, vol.1, Wiley \& Sons, Chichester, p. 1367-72. 
Bray GA 1989. Classification and evaluation of the obesities. Med Clin North Am 73: 161-84.

CDC 2004. Epidemiology Program Office. Epi-Info version 3.2.2.

Costa AA, Inenami M, Juarez E, Llacen PD, Raw I 1997. Preliminary report of the use on adults of a recombinant yeastderived hepatitis B vaccine manufactured by Instituto Butantan. Rev Inst Med Trop São Paulo 39: 39-42.

Dean AG, Dean JA, Coulombier D, Burton AH, Brendel KA, Smith DC, Dicker RC, Sullivan KM, Fagan RF 1994. Epi Info, Version 6, CDC, Atlanta, GA.

Ferreira CRB, Yoshida CFT, Mercadante LAC et al. 1993. Immunization against hepatitis $\mathrm{B}$ in children from an endemic zone: evaluation of the antibody response against the DNA recombinant vaccine (Engerix B-20mcg). Rev Inst Med Trop São Paulo 35: 89-92.

Fisman DN, Agrawal D, Leder K 2002. The effect of age on immunologic response to recombinant hepatitis B vaccine: a meta-analysis. Clin Infect Dis 35: 1368-1375.

Gadelha C, Azevedo N 2003. Vaccine innovations in Brazil: recent experiences and structural constraints. In Immunization in Brazil - History and perspectives. História, Ciências, Saúde - Manguinhos 10 (Suppl. 2): 709-712.

Greenberg DP 1993. Pediatric experience with recombinant hepatitis B vaccines and relevant safety and immunogenicity studies. Pediatr Infect Dis J 12: 438-445.

Hieu NT, Kim KH, Janowicz Z, Timmermans I 2002. Comparative efficacy, safety and immunogenicity of HepavaxGene and Engerix-B, recombinant hepatitis B vaccines, in infants born to $\mathrm{HBsAg}$ and $\mathrm{HBeAg}$ positive mothers in Vietnam: an assessment at 2 years. Vaccine 20: 1803-1808.
Ioshimoto LM, Rissato ML, Bonilha VSJ, Miyaki C, Raw I, Granovski N 1999. Safety and immunogenicity of hepatitis $\mathrm{B}$ vaccine Butang in adults. Rev Inst Med Trop São Paulo 41: 191-193.

Keating GM, Noble S 2003. Recombinant hepatitis B vaccine (Engerix B). A review of its immunogenicity and protective efficacy against hepatitis B. Drugs 63: 1021-1051.

Leroux-Roels G, Abraham B, Fourneau M, De Clercq N, Safary A 2000. A comparison of two commercial recombinant vaccines for hepatitis B in adolescents. Vaccine 19: 937-942.

Mahoney FJ, Kane M 1999. Hepatitis B vaccine. In SA Plotkin, EA Orenstein (eds), Vaccines, 3rd ed., Saunders, Philadelphia, p. 158-82.

Motta MSF, Mussi-Pinhata MM, Jorge SM, Yoshida CFT, Souza CBS 2002. Immunogenicity of hepatitis B vaccine in preterm and full term infants vaccinated within the first week of life. Vaccine 20: 1557-1562.

Saari TN 2003. Immunization of preterm and low birth weight infants. Pediatrics 112: 193-198.

Ul-Haq N, Hasnain SS, Umar M, Abbas Z, Valenzuela-Silva C, Lopez-Saura P 2003. Immunogenicity of 10 and $20 \mu \mathrm{g}$ hepatitis B vaccine in a two-dose schedule. Vaccine 21: 31793185.

Vanlandschoot P, Van Houtte F, Hoek F, Nieuwland R, LerouxRoels G 2003. Saccharomyces cerevisiae-derived HBsAg preparations differ in their attachment to monocytes, immune-suppressive potential, and T-cell immunogenicity. $J$ Med Virol 70: 513-519.

WHO 2001. Hepatitis B potency testing standardization. Report of a Meeting, WHO/SEARO, New Delhi, 9-11 April. 
